\title{
MODIFIED STARCH OF SORGHUM MUTANT LINE Zh-30 FOR HIGH FIBER MUFFIN PRODUCTS
}

\author{
D. D. S. Santosa ${ }^{1 *}$, S. Human ${ }^{2}$ \\ ${ }^{1 .}$ PT Putri Citra, Aceh Besar, Indonesia \\ ${ }^{2}$ Center for Application of Isotope and Radiation Technology, \\ National Nuclear Energy Agency (BATAN)
}

Received 26 June 2008; Received in revised form 27 August 2008; Accepted 22 December 2008

\begin{abstract}
MODIFIED STARCH OF SORGHUM MUTANT LINE ZH-30 FOR HIGH FIBER MUFFIN PRODUCTS. Sorghum mutant line Zh-30 is a breeding line developed at the Center for the Application of Isotope and Radiation Technology, BATAN by using mutation techniques. Gamma irradiation with the dose of $300 \mathrm{~Gy}$ was used to induce sorghum genetic variation. Through selection processes in several generations, the mutant line $\mathrm{Zh}-30$ was identified to have better agronomic characteristics, better grain quality and higher grain yield than the original variety. Research on modified starch quality of this mutant line was done to identify its potential use in food industry. Functionality of pregelatinized, hydroxypropyl and crosslinked starch of this mutant line (Mutant TexInstant 30) has been studied for its use in high fiber muffin products. Characteristics of high fiber muffins containing 1.50; 3.50 and 5.50\% of Mutant Tex-Instant 30 replacement levels to wheat flour were evaluated using both sensory panel and physical test methods. With regard to the sensory parameters, the high fiber muffins containing 1.50 - 5.50 \% Mutant Tex-Instant 30 in general were not significantly different compared to the standard reference muffin. Results of physical evaluations showed that all Mutant Tex-Instant 30 containing products retained more moisture during baking than the standard reference. Tenderness of all products decreased at similar rate following 24 and $48 \mathrm{hr}$ of room temperature storage and seven days at freezer temperature. These results suggested that sorghum mutant line Zh-30 starch could be modified and potentially used in food industry as a subtitute of wheat flour.
\end{abstract}

Keywords: Sorghum mutant line, starch, high fiber muffin, baked good

두 2009 Atom Indonesia. All rights reserved.

\section{INTRODUCTION}

Sorghum (Sorghum bicolor L) is cereal crop that is usually grown under hot and dry conditions. Sorghum is potential to be grown and developed in Indonesia owing to its wide adaptation, drought tolerance, low-input crop and high yielding. Sorghum is multiusage crops i.e. it can be used as food source, animal feed and raw material for industries. According to ICRISAT/FAO, as global food source sorghum ranks the fifth after wheat, rice, corn, and barley. In many countries, sorghum grains are also used for industry such as ethanol, bear, wine, syrup, paint, glue, and modified starch $[1,2]$.

\footnotetext{
Corresponding author.

E-mail addresses: agroteknobisnis@yahoo.com, (D. D. S. Santosa)
} 
Sorghum has a high yield potential, comparable to those of rice, wheat, and maize. On a field basis, yield have exceeded 11 ton/ha, with above average yields ranging from 79 ton/ha where moisture is not a limiting factor. In those areas where sorghum is commonly grown, yields of 3-4 ton/ha are obtained under normal condition. Sorghum is also known to have wide adaptability, ranging from lowland, medium and highland altitude. Highest yields are usually obtained from varieties maturing in 100-120 days. Latematuring varieties tend to be appropriate for forage crop [3].

Sorghum is believed to have high tolerance to adverse conditions such as drought. Compare to maize, sorghum has a more extensive and fibrous root system. The plant roots penetrate a greater volume of soil to obtain moisture. Fertilizer, even under low rainfall conditions, encourages root development, hence the root are able to extract moisture from a greater volume of soil. Sorghum requires less moisture for growth than some other cereal crops. A study shows that sorghum requires $332 \mathrm{~kg}$ of water per $\mathrm{kg}$ of accumulated dry matter, while maize requires $368 \mathrm{~kg}$ of water, barley $434 \mathrm{~kg}$, and wheat $514 \mathrm{~kg}$. Compared to maize, sorghum is also more tolerant to water lodging, salinity, and aluminum toxicity [4].

Indonesian agriculture has been very much hampered with water scarcity or prolonged drought during dry season. With regard to this problem, Center for Application of Isotop and Radiation Technology, BATAN has developed some drought tolerant sorghum mutants through mutation breeding program. One of the promising lines, what so called $\mathrm{Zh}-30$, was developed from Zhengzu variety originated from China by using gamma irradiation. During selection processes in several generations, this mutant line was identified to have excellent agronomic characteristic and high yielding $[5,6]$.

The Zh-30 mutant line had white grain color and its flour and starch quality was being studied for wheat flour substitution in food industry. The objective of this research was to identify the modified starch of sorghum mutant line Zh-30 (Mutant Tex-Instant 30) for its potential use in food products like muffins.

\section{EXPERIMENTAL METHODS}

Sorghum grain of $\mathrm{Zh}-30$ mutant line was provided by the Center of Application of Isotope and Radiation Technology, BATAN, Jakarta. The modified starch of sorghum $\mathrm{Zh} 30$ grain was prepared at the Laboratory of Food Technology, Gadjah Mada University in Yogyakarta. Some materials such as MS-DS were kindly supplied by Bogasari Baking Center (BBC), and lndomilk in Jakarta.

The sorghum starch was modified by pregelatinizing, hydroxypropyl and crosslinking with MS-DS 0, I07 - 0,125 (Mutant Tex-Instant 30). Characteristics of high fiber muffins containing $1.50 ; 3.50$ and $550 \%$ of 
Mutant Tex-Instant 30 were evaluated using physical test methods and sensory panel, in collaboration with research counterparts at the Center for Agricultural Postharvest Research and Development in Bogor.

A high fiber standard muffins formulation was used to prepare the products. The ingredients (on percent flour basis) were as follows: $22.30 \%$ sugar (powder); $7.40 \%$ margarine; $4.80 \%$ canola oil; $0.20 \%$ lecithin; $14.00 \%$ whole eggs; $17.60 \%$ water; $19.30 \%$ wheat flour; $1.90 \%$ skimmed milk powder; $1.50 \%$ baking powder; $0.05 \%$ tara gum; $0.05 \%$ locust bean gum, and $0,20 \%$ salt. Subsitution of wheat flour with Mutant Tex-Instant 30 of $1.50 \%$, $3.50 \%$, and $5.50 \%$ was applied as treatments in this experiment. Each treatment was replicated three times with two samples per replication.

The mixing of ingredients was done using kitchen aid mixer, and whipping at speed of $120 \mathrm{rpm}$ for 1 minute. The sifted dry ingredients were added and blended using the flat paddle. Samples of mixture (batter) were weighed into each muffin cup of an aluminum pan that had been sprayed with a nonstick pan coating substance. Products were baked in preheated oven of $205^{\circ} \mathrm{C}$ for 15 minutes. Following a 5-min setting period, the muffins were removed from the pans and allowed to coolon wire racks for $1 \mathrm{hr}$ before being packaged in moisture and vapor proof wrap material for use in various physical and sensory tests. Products to be evaluated 24 and $48 \mathrm{hr}$ after baking were stored at room temperature, whereas those evaluated one week after baking were stored at $-10^{\circ} \mathrm{C}$. The frozen samples were thawed, covered, at room temperature for $24 \mathrm{hr}$ prior to testing.

Nine quality characteristics were evaluated for each high fiber muffin by sensory comparation to the $100 \%$ wheat flour reference standard product. These characteristics included height, appearance of exterior surface, exterior color, grain, moistness, mouthfeel, interior color, tenderness, and flavor. The 1-9 standard evaluation score was used by panelists to judge each sensory characteristic value. Score I indicated that the quality was too less below the standard, whereas score 9 was too much over the standard sensory characteristics. Score 5 represented a complete match of the quality characteristic between the treatment and the reference standard of high fiber muffin [7-9].

Physical tests were performed 24 and $48 \mathrm{hr}$ after baking and after seven days of frozen storage. The observed parameters included tenderness, texture pressure, penetrometer, standing height, volume, weight lost during baking, and color measurements. Volume was determined using the rapeseed displacement method. Ruler measurements determined the standing height of each item. Penetrometer values were measured using 65-mm, 14-g cone and texture press readings. Color measurements with colorimeter were recorded for all samples from previously frozen products, following the standard methods $[10,11]$. 


\section{RESULT AND DISCUSSION}

Result of sensory characteristic test for different percent substitution of Mutant Tex-Instant 30 in the ingredients of muffins was presented in Table 1. The data were summarized for the mean values and their standard error from results of the analysis of variance. In general, there was significantly different between percent substitution levels of Mutant Tex-Instant 30 in the ingredients of muffins for the parameter observed. The data showed that the percent substitution levels of $1.50-5.50 \%$ could match the reference standard of the high fiber muffins with the score value ranged from 4.0 to 5.2. At substitution level of $1.50 \%$, the closest maching was found for the parameters of height, grain and flavor. Results indicated that the parameters of internal color, moistness, terderness and flavor of the tested muffins were closely matching the reference standard. It means that the Mutant Tex-Instant 30 made from sorghum mutant line $\mathrm{Zh}-30$ could subtitute that one of wheat flour starch commonly used in food industry. It would be beneficial since Indonesia had so far been importing wheat in big amount i.e. more that 4 million tons a year [12]. By developing sorghum, especially the mutant line Zh-30, Indonesia might reduce wheat import and promote more sorghum-base food industry. In turn, it would promote employments and increase farmers' income in the country.

Table 1. The mean values of sensory characteristics for different percent substitution of Mutant Tex-Instant 30 in the ingredients of muffins (mean \pm SE)

\begin{tabular}{|l|c|c|c|}
\hline \multicolumn{1}{|c|}{ Parameters } & \multicolumn{3}{|c|}{ Substitution } \\
\cline { 2 - 4 } & $\mathbf{1 . 5 0 \%}$ & $\mathbf{3 . 5 0 \%}$ & $\mathbf{5 . 5 0 \%}$ \\
\hline Height & $5.0^{\mathrm{a}} \pm 0.10$ & $4.5^{\mathrm{b}} \pm 0.15$ & $4.3^{\mathrm{c}} \pm 0.13$ \\
\hline External surface & $4.4^{\mathrm{a}} \pm 0.15$ & $4.2^{\mathrm{b}} \pm 0.13$ & $4.0^{\mathrm{c}} \pm 0.12$ \\
\hline External color & $4.3^{\mathrm{a}} \pm 0.15$ & $4.1^{\mathrm{a}} \pm 0.16$ & $4.0^{\mathrm{b}} \pm 0.20$ \\
\hline Internal color & $4.6 \pm 0.11$ & $4.7 \pm 0.19$ & $4.6 \pm 0.16$ \\
\hline Grain & $4.8^{\mathrm{a}} \pm 0.23$ & $4.5^{\mathrm{b}} \pm 0.22$ & $4.5^{\mathrm{b}} \pm 0.21$ \\
\hline Moistness & $4.6^{\mathrm{a}} \pm 0.13$ & $5.0^{\mathrm{b}} \pm 0.18$ & $5.2^{\mathrm{c}} \pm 0.13$ \\
\hline Mouthfeel & $4.5^{\mathrm{a}} \pm 0.11$ & $4.2^{\mathrm{b}} \pm 0.12$ & $4.0^{\mathrm{c}} \pm 0.14$ \\
\hline Tenderness & $4.6 \pm 0.16$ & $4.5 \pm 0.18$ & $4.5 \pm 0.18$ \\
\hline Flavor & $5.0 \pm 0.15$ & $4.8 \pm 0.19$ & $4.7 \pm 0.22$ \\
\hline
\end{tabular}

Means within rows followed by different letters are significantly different $(\mathrm{P}<0.01)$

Volume of the high fiber muffins was not influenced by treatment. Both visual comparations of test high fiber muffins to the reference standard by the panel (Table 1) and the standing height measurements (Table 2) revealed that the $1.50 \%$ substitution product was significantly $(\mathrm{P}>0.01)$ taller than the other products. Panelists rated both the 3.50 and $5.50 \%$ substitution level products to be significantly $(\mathrm{P}>0.01)$ lower; however, 
standing height measurement indicated that only the $5.50 \%$ substitution product was significantly $(\mathrm{P}>0.01)$ lower than the reference standard.

Table 2. The mean values of on physical characteristics for different percent substitution of Mutant Tex-Instant 30 in the ingredients of muffins (mean $\pm \mathrm{SE})$

\begin{tabular}{|l|c|c|c|c|}
\hline \multirow{2}{*}{ Parameter } & \multicolumn{4}{|c|}{ Percent Substitution } \\
\cline { 2 - 5 } & $\mathbf{0}$ & $\mathbf{1 . 5 0}$ & $\mathbf{3 . 5 0}$ & $\mathbf{5 . 5 0}$ \\
\hline Texture Press $(\mathrm{lb} / \mathrm{gm})$ & $1.1^{\mathrm{a}} \pm 0.06$ & $1.2^{\mathrm{a}} \pm 0.06$ & $1.2^{\mathrm{a}} \pm 0.03$ & $1.4^{\mathrm{a}} \pm 0.03$ \\
\hline Penetrometer $(0,1 \mathrm{~mm})$ & $132.2^{\mathrm{a}} \pm 5.18$ & $132.0^{\mathrm{b}} \pm 3.07$ & $131.5^{\mathrm{a}} \pm 6.05$ & $131.4^{\mathrm{a}} \pm 5.15$ \\
\hline Standing Height $(\mathrm{mm})$ & $39.0^{\mathrm{b}} \pm 0.16$ & $42.4^{\mathrm{a}} \pm 0.06$ & $40.3^{\mathrm{b}} \pm 0.43$ & $36.8^{\mathrm{c}} \pm 0.37$ \\
\hline Weight Lost $(\mathrm{g})$ & $9.5^{\mathrm{c}} \pm 0.10$ & $7.8^{\mathrm{a}} \pm 0.19$ & $7.7^{\mathrm{a}} \pm 0.20$ & $7.5^{\mathrm{b}} \pm 0.28$ \\
\hline Volume $(\mathrm{ml})$ & $53.8^{\mathrm{a}} \pm 2.20$ & $53.7^{\mathrm{b}} \pm 1.62$ & $52.2^{\mathrm{a}} \pm 2.10$ & $51.2^{\mathrm{a}} \pm 1.75$ \\
\hline
\end{tabular}

Means within rows followed by different letters are significantly different $(\mathrm{P}<0,01)$

The significantly difference in volume and height characteristics may be inferred from the panelists evaluation and written descriptions of the external characteristics of the high fiber muffins. They found significantly differences $(\mathrm{P}>0.01)$ in the external appearance of the high fiber muffins as a result of treatment. Table I shows that the panel judged the external surface of the products to be less similar to the standard as the level of Mutant Tex-Instant 30 substitution increased. Panel members commented that the top surface of the products became broader and flatter as the level of the Mutant Tex-Instant 30 substitution increased. It is apparent that the broader shape of the high fiber muffins compensated for the decreased height, allowing no significant differences to be noted in the volume of the products.

Based on both sensory panel and physical test data (Tables 1 and 2), the products containing Mutant Tex-Instant 30 were significantly $(\mathrm{P}>0.01)$ more moist than the reference standard high fiber muffins. The $5.50 \%$ replacement products retained significantly $(\mathrm{P}>0.01)$ more moisture during baking than the other products and was evaluated by the panel as being significantly $(\mathrm{P}>0.01)$ more moist; however, panelists found this level to be excessive, because several members described this item as being "wet" or "mushy."

Table 1 shows that significant differences $(\mathrm{P}>0.01)$ were found in the panel's response to the mouthfeel characteristics of the high fiber muffins. As the level of Mutant Tex-Instant 30 substitution in the products increased, the rating scores decreased. Additionally, panelists written comments describing the mouthfeel reflected this trend.

The sensory panel did not find a statistically significant difference in flavor between the test high fibre muffins and the reference standard or among the test high fibre muffin. 
Results of texture press and penetrometer (Table 2) data reveal that no significant differences were found between the standard and the test high fiber muffins, or among the test high fiber muffins as a result of level of Mutant Tex-Instant 30 substitution. This finding is supported by sensory panel data indicating that unlike the nonwaxy source, Mutant Tex-Instant 30 does not contribute to a decrease in products tenderness. The sensory panel noted significant differences in the grain of the products. The $1.50 \%$ substitution level product was rated as being closer to the reference standard. The panel did not a significant difference in the grain of the products containing 3.50 and $5.50 \%$ replacement levels.

The quality of muffin products would also influenced by their color, either internal or external color. Data of color measurements for different percent substitution of Mutant Tex-Instant 30 in the ingredients of muffins (for external and internal color) were presented in Table 3. External color was very important properties for muffin products as it would determine the attractive performance to consumers. It was shown that there was not much significantly different between the treatments (percent subsitution of Mutant Tex-Instant 30) and the control or reference standard muffin. This indicated that application of Mutant Tex-Instant 30 gave mostly external and internal color performances similar to that of the standard muffin. Significant differences in color were found only for redness of exterior surfaces and lightness of the interior of the products. Products having higher levels of Mutant Tex-Instant 30 had significantly less redness than the reference standard products. Colorimeter values revealed that only the $5.50 \%$ Mutant Tex-Instant 30 substitution products had a significantly darker internal color than the other samples.

Table 3. The mean values of on physical characteristics for different percent substitution of Mutant Tex-Instant 30 in the ingredients of muffins (mean $\pm \mathrm{SE})$

\begin{tabular}{|c|c|c|c|c|c|}
\hline \multicolumn{2}{|c|}{ Parameters } & \multicolumn{4}{c|}{ Percent Substitution } \\
\cline { 3 - 6 } \multicolumn{2}{|c|}{} & $\mathbf{0}$ & $\mathbf{1 . 5 0}$ & $\mathbf{3 . 5 0}$ & $\mathbf{5 . 5 0}$ \\
\hline \multirow{3}{*}{ External } & $\mathrm{L}$ & $57.95^{\mathrm{a}} \pm 0.586$ & $59.58^{\mathrm{a}} \pm 0.546$ & $59.23^{\mathrm{a}} \pm 0.253$ & $59.74^{\mathrm{a}} \pm 0.363$ \\
\cline { 2 - 6 } & $\mathrm{A}$ & $2.28^{\mathrm{a}} \pm 0.68$ & $2.08^{\mathrm{a}} \pm 0.097$ & $1.55^{\mathrm{b}} \pm 0.095$ & $1.43^{\mathrm{b}} \pm 0.145$ \\
\cline { 2 - 6 } & $\mathrm{B}$ & $21.80^{\mathrm{a}} \pm 0.252$ & $21.14^{\mathrm{a}} \pm 0.328$ & $21.13^{\mathrm{a}} \pm 0.289$ & $21.82^{\mathrm{a}} \pm 0.268$ \\
\hline \multirow{3}{*}{ Internal } & $\mathrm{L}$ & $68.85^{\mathrm{a}} \pm 0.256$ & $68.48^{\mathrm{a}} \pm 0.146$ & $67.33^{\mathrm{a}} \pm 0.253$ & $66.74^{\mathrm{b}} \pm 0.263$ \\
\cline { 2 - 6 } & $\mathrm{A}$ & $-1.38^{\mathrm{a}} \pm 0.035$ & $-1.26^{\mathrm{a}} \pm 0.055$ & $-1.24^{\mathrm{a}} \pm 0.039$ & $-1.12^{\mathrm{a}} \pm 0.044$ \\
\cline { 2 - 6 } & $\mathrm{B}$ & $17.50^{\mathrm{a}} \pm 1.000$ & $17.56^{\mathrm{a}} \pm 0.068$ & $17.40^{\mathrm{a}} \pm 0.050$ & $17.38^{\mathrm{a}} \pm 0.092$ \\
\hline
\end{tabular}

Means within rows followed by different letters are significantly different $(\mathrm{P}<0.01)$

L : white - black

$\mathrm{a}$ : green - red

b : blue - yeloow

Means Square Error (MSE) for external : $\mathrm{L}=5.371, \mathrm{a}=3.231, \mathrm{~b}=0.868$

Means Square Error (MSE) for internal : $\mathrm{L}=0.694, \mathrm{a}=0.019, \mathrm{~b}=0.124$ 
Significant differences in color were found only for redness of external surfaces and lightness of the interior of the products. Products having higher levels of Mutant Tex-Instant 30 had significantly $(\mathrm{P}>0.01)$ less redness than the standard and $1.50 \%$ replacement products. Panelist noted (Table 1) that these products were significantly different $(\mathrm{P}>0.01)$ than the standard but did not describe the difference. Colorimeter values (Table 3) revealed that only 5.50\% Mutant Tex-Instant 30 substitution products had a significant darker $(\mathrm{P}>0.01)$ interior than the other samples. However, sensory panel data revealed a significant $(\mathrm{P}>0.05)$ interaction between storage time and treatment with respect to internal color $[11,13]$.

It was of interesting to know the relationship between percent substitution of Mutant Tex-Instant 30 and the tenderness of muffin products during different storage times. Tenderness was measured by texture pressure $(\mathrm{lb} / \mathrm{g}$ ) and penetrometer (with equipment of $0.1 \mathrm{~mm}$ scale). The lower the texture presure and the higher the penetrometer values, the more tender the muffin product would be. As shown at data in Table 4, there was no significant difference between percent substitutions of Mutant Tex-Instant 30 for the tenderness of muffin products at storage time of $24 \mathrm{hr}, 48 \mathrm{hr}$ and 7 days. It could be concluded that modified strach of sorghum mutant line $\mathrm{Zh}-30$ gave results in terderness just as good as that of the standard reference muffin.

Measurements of tenderness (texture press and penetrometer) indicated that storage time had a significant $(\mathrm{P}>0.01)$ effect on the tenderness characteristic. The analysis shown in Table 4 revealed that a similar level of tenderness existed between the products stored for $24 \mathrm{hr}$ at room temperature and seven days in frozen storage regardless of Mutant Tex-Instant 30 substitution level. In all instances the products stored for $48 \mathrm{hr}$ at room temperature were significantly $(\mathrm{P}>0.01)$ less tender than the other products.

Table 4. The mean values of tenderness for different percent substitution of Mutant Tex-Instant 30 in the ingredients of muffins at various storage time

\begin{tabular}{|l|c|c|c|}
\hline \multirow{2}{*}{$\begin{array}{c}\text { Tenderness/ } \\
\text { Persen Substitution }\end{array}$} & \multicolumn{3}{|c|}{ Storage Time } \\
\cline { 2 - 4 } & $\mathbf{2 4} \mathbf{~ h r}$ & $\mathbf{4 8 ~ h r}$ & $\mathbf{7 ~ D a y s}$ \\
\hline Texture press, (1b/g) & & & \\
\hline $0 \%$ & $0.7^{\mathrm{a}}$ & $1.4^{\mathrm{b}}$ & $0.8^{\mathrm{a}}$ \\
\hline $1.50 \%$ & $0.8^{\mathrm{a}}$ & $1.4^{\mathrm{b}}$ & $0.9^{\mathrm{a}}$ \\
\hline $3.50 \%$ & $0.9^{\mathrm{a}}$ & $1.3^{\mathrm{b}}$ & $0.9^{\mathrm{a}}$ \\
\hline $5.50 \%$ & $0.8^{\mathrm{a}}$ & $1.2^{\mathrm{b}}$ & $0.9^{\mathrm{a}}$ \\
\hline Mean & $0.8^{\mathrm{a}}$ & $1.2^{\mathrm{b}}$ & $0.9^{\mathrm{a}}$ \\
\hline Penetrometer $(0,1 \mathrm{~mm})$ & & & $151^{\mathrm{a}}$ \\
\hline $0 \%$ & $150^{\mathrm{a}}$ & $115^{\mathrm{b}}$ & $143^{\mathrm{a}}$ \\
\hline $1.50 \%$ & $135^{\mathrm{a}}$ & $114^{\mathrm{b}}$ & $144^{\mathrm{a}}$ \\
\hline $3.50 \%$ & $143^{\mathrm{a}}$ & $113^{\mathrm{b}}$ & $146^{\mathrm{a}}$ \\
\hline $5.50 \%$ & $148^{\mathrm{a}}$ & $114^{\mathrm{b}}$ & $144^{\mathrm{a}}$ \\
\hline Mean & $146^{\mathrm{a}}$ & $116^{\mathrm{b}}$ & \\
\hline
\end{tabular}

Means within rows followed by different letters are significantly different $(\mathrm{P}<0.01)$ 
Based on data obtained from this study and previous one, it can be concluded that Mutant Tex-Instant 30 aids in the retention of moisture during baking and does not contribute to maintenance of tenderness during room temperature storage when the products are not reheated prior to evaluation. Retrogradation can be reversed to some extent by heat energy in the presence of moisture or other lubricating substances [14-16]. Therefore, it can be speculated that the greater retention of moisture in the Mutant Tex-Instant 30 products might contribute to a reversal of retrogradation if the products were heated prior to testing.

\section{CONCLUSION}

For the sensory test parameters, the high fiber muffins containing $1.50-5.50 \%$ Mutant Tex-Instant 30 in general were not significantly different compared with the standard reference muffin. Results of physical evaluations showed that all Mutant Tex-Instant 30 containing products retained more moisture during baking than the standard reference. Tenderness of all products decreased at similar rate following 24 and $48 \mathrm{hr}$ of room temperature storage and seven days at freezer temperature. The parameters of external and internal color, moistness, terderness, volume and flavor of the tested muffins were closely matching to the reference standard. With regard to those parameters, the modified strach of sorghum mutant line Zh-30 gave results just as good as that of the standard reference muffin. It was concluded that the modified starch of sorghum mutant line $\mathrm{Zh}$-30 could subtitute that of wheat flour commonly used in food industry so far.

\section{ACKNOLEDGEMENT}

We would like to thank Mr. Jusuf Sutanto for facilitating the analysis of our sorghum starch at PT. Bogasari Flour Mills Tbk., and also through demonstration at Bogasari Baking Center. Also, we thank the Laboratory of Food Technology, Gadjah Mada University in Yogyakarta for preparing sorghum modified starch.

\section{REFERENCES}

1. ICRISA T/F AO., : "The World Sorghum and Millet Economies: Facts, trend and outlook", Published by FAO and ICRISAT, 68 (1996).

2. ICRISA T., Proceedings of Symposium on the Current Status and Potential of Industrial Uses of Sorghum, 59 (1990). 
3. RANA, B.S. and RAO, M.H., Technology for increasing sorghum production and value addition, National Research Center for Sorghum, Indian Council of Agricultural Research. Hyderabad, India, 65 (2000).

4. HOUSE, L. R., International Crops Research Institute for Semi-Arid Tropics, Andhra Pradesh, India, ICRISA T/F AO., 238 (1985).

5. SOERANTO, H., NAKANISHI, T.M. and RAZAK, M.T., Journal Radioisotopes, 52 (1) (2003).

6. SOERANTO, H., NAKANISHI, T.M., PARNO and SIHONO, Proceedings of the 3rd Seminar Toward Harmonization between Development and Environmental Conservation in Biological Production. JSPSDGHE Core University Program in Applied Biosciences., IPB Bogor and the University of Tokyo, Serang, Banten, 3-5 December (2004).

7. JOHNSON, D. P., Analitical Chemistry, 4 (1) 859 - 880 (1969).

8. YEH, A and YEH, S., Cereal Chemistry, 70, 596 - 601 (1993).

9. KIM, H. R., HERMANSSON, A. M. and ERIKSSON, C.E., Analitical Chemistry, 44, 111-116 (1992).

10. JOHNSON, D. P., Analitical Chemistry, 41, 859 - 880 (1969).

11. NEWSOME, R. L., : "Natural and synthesis coloring agents", In Branen, A. L., Davidson, P. M. Dan Salminen, S. Food Additives, Marcel Dekker, Inc, New York and Basel, (1990).

12. DEPARTEMEN PERTANIAN, : "Program pengembangan gandum tahun 2005", Direktorat Serealia, Dirjen Bina Produksi Tanaman Pangan, Makalah Rapat Koordinasi Penelitian dan Pengembangan Gandum, Jakarta, 8 Februari (2005).

13. HARDMAN, T. M., : "Elsevier Applied Science", London and New York, (1989).

14. JANE, J., XU, A., RADOSA VILJEVIE, M. and SEIB, P. A., Cereal Chemistry, 69, 405 - 409 (1992).

15. RUTTENBERG, M. W. and SOLAREK, D., : "Chemistry and Technology", Ed. R. L. Whistler. J. N. BeMiller, and E. F. Paschall, Academic Press, Toranto, 311 - 388 (1984).

16. TOLEDO, R. T., : "Fundamentals of Food Process Engineering (2nd ed.)", Chapman and Hall, New York, (1991). 